\title{
Exclusion testing in pregnancy for Huntington's disease
}

\author{
A Tyler, O W J Quarrell, L P Lazarou, A L Meredith, P S Harper
}

\begin{abstract}
The results of DNA analysis are presented for a series of 90 couples, with one partner at $50 \%$ risk for Huntington's disease (HD), who were referred for exclusion testing in pregnancy over a three year period. Thirty-seven couples were studied in detail. The aims of the study were to evaluate attitudes towards prenatal testing, before pregnancy and afterwards, and the effectiveness of our counselling and methods of organising the service. Problems which could arise in relation to presymptomatic testing are documented.

It is concluded that exclusion testing is a valuable form of prediction for some couples, particularly where family structure does not permit prediction for the person at risk. The need for intensive counselling was highlighted by the difficulties experienced by many couples in understanding how the test worked. Particular ethical and organisational problems may arise which require careful consideration beforehand and some recommendations are made. The proportion of couples who will continue to request exclusion testing as presymptomatic testing becomes more widely applicable remains unknown.
\end{abstract}

Huntington's disease (HD) is a severe, progressive, neurodegenerative disorder with complete penetrance, which is inherited in an autosomal dominant manner. The age of onset is variable but most cases present between the ages of 35 and 55 years. The identification of a closely linked DNA restriction fragment length polymorphism on chromosome $4^{1}$ has, for the first time, permitted predictive testing for family members at risk.

There are two ways in which a DNA marker closely linked to the HD locus can be clinically applied:

Institute of Medical Genetics, University Hospital of Wales, Heath Park, Cardiff CF4 4XW.

A Tyler, O W J Quarrell, L P Lazarou, A L Meredith, P S Harper

Correspondence to Miss Tyler.

Received for publication 3 July 1989.

Revised version accepted for publication 8 March 1990. presymptomatic testing for the individual subject, and exclusion testing in pregnancy, which alters the risk to the fetus but leaves unchanged the parents' risk. ${ }^{2}$ Both types of testing depend on a linkage study, but the requirements in terms of family structure are much more easily met for prenatal testing than for presymptomatic testing. ${ }^{3}$ Thus, family members who want to have children at low risk for HD (in the absence of recombination) may choose prenatal testing because their family structure is inadequate for prediction for themselves, or because they do not wish to alter their own risk.

While considerable discussion has taken place regarding presymptomatic testing, ${ }^{4-6}$ with some preliminary results reported, ${ }^{7-9}$ exclusion testing has received much less consideration although this type of testing raises specific ethical and counselling issueso not applicable to prediction for the individual subject.

Results are presented for a series of 90 couples referred over three years for consideration of exclusion testing in pregnancy; we have previously reported on nine pregnancies occurring in this series ${ }^{10}$ and that number had risen to 19 by May $1988 .{ }^{11}$ Thirty-seven couples have been studied in detail. The aims of the study were to evaluate attitudes toward prenatal testing, before pregnancy and afterwards, to test the effectiveness of our counselling, and the organisational aspects of our protocol, and to gain experience in problems related to the presymptomatic testing project which was then being developed.

The numbers in the study were too small to permit correlation of the clinical and demographic data with attitudes towards and outcomes of testing: this awaits a larger longitudinal study.

\section{Patients and methods}

These have been briefly described previously in a report on 55 couples referred for pre-pregnancy typing $^{10}$; the series has been extended by 35 in the present, more detailed study.

Over a three year period, a total of 90 couples with one partner at $50 \%$ risk has been referred for exclusion testing in pregnancy; 15 from within the authors' own region (Wales) and 75 from genetic centres in England. Pre-pregnancy and prenatal test results, together with pregnancy outcomes, are pre- 
sented. Thirty-seven couples have been studied in detail by two of us (AT and OQ); demographic and clinical data were collected, their exposure to HD and understanding of the test evaluated, and their attitudes towards testing explored. Although detailed psychosocial data were not collected on the total group, it is not thought that the couples studied are likely to differ significantly from the rest.

In the study group, 15 patients were from Wales and 22 came from outside the region. All had been counselled previously, either by the referring genetic centre or were already known to two of us (AT and $\mathrm{OQ}$ ). In 33 cases the diagnosis of HD in the parent of the consultand was confirmed by review of medical records supported by a family history. In four cases the clinical criteria were met, but information on previous generations was lacking. These couples were advised to wait for necropsy to support or disprove the presumptive diagnosis, but three decided to continue with pre-pregnancy testing for informativeness. At least two interviews, lasting between one and two hours each, were arranged; couples normally came together and one joint interview was mandatory before prenatal testing was undertaken. At the first interview(s) basic clinical and demographic information relating both to the at risk person and his/her partner was collected. The couple were also encouraged to describe their experience and understanding of the illness and how long they had known about the diagnosis in the affected parent.

A full explanation of the testing procedure was given. It was stressed that the risk to the fetus could be raised to the parent's risk or lowered to less than $3 \%$, but that the parent's risk remained unchanged, and that if termination of pregnancy was unacceptable the test was inappropriate. The possibility of a 'partially informative' situation was also discussed. Attitudes towards predictive testing and other options were explored. Publications describing the test and the procedure of chorion biopsy, including the risks, were always offered.

When the results of testing for informativeness were known, a further interview was arranged and the couple's understanding of and attitudes towards prenatal testing evaluated.

On notification of a pregnancy, transcervical or transabdominal chorion villus biopsy was used to obtain fetal DNA samples at 8 to 10 weeks' gestation. Biopsy results were notified to the referring genetic centre, usually within two weeks. For the Welsh patients, results were given face to face (never over the telephone) and where termination was appropriate it was performed the day after. All the Welsh patients were followed up afterwards.

The method of DNA analysis and fetal sampling has been described elsewhere, ${ }^{10}$ but the number of polymorphisms available for study has increased to 18 (table 1).

\section{Results}

PRE-PREGNANCY TESTING RESULTS

These are summarised in table 2 . Three of the 10 couples who received an uninformative or partially informative result have asked for testing to be continued. Since the series extended over a three year period, it is likely that the number of uninformative, or partially informative, couples could be further reduced by the use of all recently available probes.

\section{PRENATAL TESTING RESULTS}

Fifteen couples have chosen prenatal testing in 24 pregnancies. The risk to the fetus was raised in 10 pregnancies and all these pregnancies have been terminated. In 14 cases the fetus was given a low risk: 10 pregnancies have come safely to term, one miscarried, and three are continuing.

Five women have been biopsied more than once. Two women, given a high risk in a first pregnancy, achieved a low risk in a second pregnancy. One woman bore a first child at low risk, terminated a second pregnancy at high risk, and a third low risk pregnancy is continuing. After miscarrying, another woman terminated a high risk pregnancy and eventually

Table 1 Probes used in exclusion testing.

\begin{tabular}{|c|c|c|}
\hline Probe & Polymorphism & \\
\hline $\begin{array}{l}\text { PKO83 } \\
\text { PKO82 }\end{array}$ & $\begin{array}{l}\text { EcoRI } \\
\text { HindIII } \\
\text { NCiI }\end{array}$ & \multirow[t]{3}{*}{$\begin{array}{l}\text { Dr J Gusella } \\
\text { Boston }\end{array}$} \\
\hline R7 & $\begin{array}{l}\text { PstI } \\
\text { BglI } \\
\text { HindIIII }\end{array}$ & \\
\hline $\begin{array}{l}\text { C4H } \\
(\mathrm{Xp500)} \\
(\mathrm{pKP165)}\end{array}$ & $\begin{array}{l}M s p I \\
B g l I\end{array}$ & \\
\hline Tu20 & PvulI & $\begin{array}{l}\text { Dr L Carlock } \\
\text { Detroit }\end{array}$ \\
\hline F5.52 & $M s p I$ & \multirow{2}{*}{$\begin{array}{l}\text { Dr P Pearson } \\
\text { Leiden }\end{array}$} \\
\hline F5.53 & $\begin{array}{l}\text { EcoRI } \\
\text { AvaII/SinI }\end{array}$ & \\
\hline 674 & $\begin{array}{l}\text { AccI } \\
\text { MboI } \\
\text { TaqI } \\
\text { PstI } \\
\text { HindIII }\end{array}$ & $\begin{array}{l}\text { Dr J Wasmuth } \\
\text { Irvine }\end{array}$ \\
\hline
\end{tabular}

Table 2 Pregnancy exclusion testing: pre-pregnancy results.

\begin{tabular}{lrr}
\hline & No & $\%$ \\
\hline Informative & 61 & 68 \\
Uninformative & 7 & 8 \\
Partially informative & 3 & 3 \\
Awaited & 3 & 3 \\
Withdrew from study & 16 & 18 \\
Total & 90 & \\
\hline
\end{tabular}


bore a child at low risk. Another woman achieved a low risk result in a fourth pregnancy, which is continuing, after terminating three pregnancies at high risk. However, some applicants for prenatal testing have expressed worries over the effect of repeated intervention during pregnancy on future health and fertility; few could envisage themselves undergoing more than two terminations. The husband of one woman who underwent termination sought presymptomatic testing in the hope that further prenatal testing would not be necessary. However, his result was adverse.

All high risk pregnancies have been terminated by currettage except in two cases where a prostaglandin termination was necessary because of a late result. Although one patient had a history of phobic anxiety, she suffered no recurrence of symptoms, even when the surroundings in which the termination took place were unusually distressing. However, she and her husband needed considerable explanation and reassurance before they embarked on a second pregnancy.

\section{WITHDRAWAL FROM EXCLUSION TESTING}

Sixteen couples changed their minds early on, and therefore their samples were not analysed. One of these couples, where the husband was at risk, asked for their 2 year old son to be tested because of the mother's difficulty in relating to him. She was unaware of the family history before becoming pregnant and had been unable to bond to the baby ever since the General Practitioner had informed her of the risk. Their request was declined and the marriage broke up shortly afterwards. The husband would have sought presymptomatic testing but his family structure was inadequate. Two other couples would have needed reversal of a sterilisation procedure had they chosen prenatal testing; one at risk partner has now been confirmed to be affected.

Seven of these couples withdrew when the DNA analysis was incomplete and thus five results were still uninformative and two partially informative. For five couples the family structure was less than ideal as one parent was missing in each case (non-paternity was responsible for one of these). Another couple was referred when already pregnant and the other conceived within three months of the referral; the time was insufficient to obtain an informative result and both women elected to continue with their pregnancies. Subsequently, all seven couples asked for further testing to be abandoned; four women have subsequently had children, one has decided not to have more children, one is pregnant, and one woman, who miscarried, has since broken off the relationship with the at risk partner so further testing is irrelevant.

Seven other couples received an informative prepregnancy result but decided against prenatal testing before becoming pregnant. Two will not have children or further children; one of these couples has chosen AID. Three have had children; one is actively trying to become pregnant and one has chosen presymptomatic testing instead, as the family structure is suitable. Five further women declined prenatal testing after becoming pregnant but before chorion villus sampling was undertaken.

The reasons why prenatal testing was not preferred, after initial interest was expressed, are known for 18 couples and are set out in table 3. Many couples had more than one reason: the most important was dislike of termination of pregnancy, given by 16 couples $(89 \%)$, some of whom had been influenced by a previous termination. Other contributory factors related to children already born; two women worried about the effect on the first child if the second child's risk status was different. Two felt that they could not afford a termination of pregnancy as they did not want to increase the age gap between first and second children. Maternal age, which referred to age 29 and over, was also influential. Five women felt that they could not afford to lose a baby at that age.

FURTHER RESULTS FOR 37 COUPLES STUDIED IN DETAIL Demographic data

The at risk group divided into 21 females and 16 males, in the age range 20 to 37 years. Their partners were in a similar age group. Just over $50 \%$ were their late twenties and early thirties. It is noteworth that there were no teenagers in this series.

Table 3 Reasons for withdrawal from pregnancy exclusion testing ( $n=18$ couples) (many couples had more than one reason).

\begin{tabular}{|c|c|c|c|}
\hline & & No & $\%$ \\
\hline $\begin{array}{l}\text { Termination of pregnancy } \\
\text { Per se } \\
\text { Previous termination } \\
\text { Possibly unaffected fetus }\end{array}$ & $\begin{array}{l}(8) \\
(4) \\
(4)\end{array}$ & 16 & 89 \\
\hline Maternal age & & 5 & 28 \\
\hline Prefer presymptomatic test & & 5 & 28 \\
\hline $\begin{array}{l}\text { Children already born } \\
\text { Age of first child vis } \\
\text { a vis a second } \\
\text { Risk position of first } \\
\text { child vis a vis a second }\end{array}$ & $\begin{array}{l}(2) \\
(2)\end{array}$ & 4 & 21 \\
\hline $\begin{array}{l}\text { Results } \\
\text { Partially informative } \\
\text { Uninformative }\end{array}$ & $\begin{array}{l}(1) \\
(2)\end{array}$ & 3 & 21 \\
\hline $\begin{array}{l}\text { Miscarriage rate associated } \\
\text { with chorion biopsy }\end{array}$ & & 3 & 21 \\
\hline Religious grounds & & 2 & 11 \\
\hline Error rate in test & & 1 & 6 \\
\hline Unconfirmed family history & & 1 & 6 \\
\hline Total & & 40 & \\
\hline
\end{tabular}


Over half the subjects belonged to social classes I and II, contrasting with the distribution found by an earlier study of HD in South Wales, ${ }^{12}$ and with the distribution in the general population ${ }^{13}$ (table 4). Non-manual workers (33) outnumbered manual workers (14) by more than two to one. Seven at risk subjects and six spouses (19\%) were graduates or the equivalent, and a further 21 and 26 respectively $(63 \%)$ had gained some educational or training qualifications; only $14(19 \%)$ possessed no educational qualifications of any sort.

Twenty-nine couples (78\%) were already married; three subjects (one at risk man and two spouses) had contracted second marriages after divorce. None had been widowed. Eight (22\%) were single but were either intending to marry or were in a long term relationship. Couples had known each other for from two to 15 years and $23(62 \%)$ had been together for over four years.

At the time of referral, 10 couples $(27 \%)$ had already had one child and there were two stepchildren. None had had more than one. Five women at risk $(14 \%)$ had already undergone terminations of pregnancy: two for social reasons, two because of the family history, one because of a combination of medical and genetic factors. The ex-wife of one man at risk had had a pregnancy terminated for social reasons.

Five couples were not using any contraceptive methods at the time of referral and two women were already pregnant, but one pregnancy was not known about at the time.

\section{Clinical data}

Past medical history indicated no significant physical problems; the great majority of applicants considered themselves to be in good health and only four admitted to being on long term medication (three for asthma and one for hypothyroidism).

At the time of referral, six subjects at risk (three men, three women) gave a recent history of experiencing significant symptoms of depression and anxiety, but only one had seen a psychiatrist, after taking a

Table 4 Social class of couples referred (study group only).

\begin{tabular}{|c|c|c|c|c|c|}
\hline & \multicolumn{2}{|c|}{$\begin{array}{l}\text { A/R subjects } \\
\text { (this study) }\end{array}$} & \multicolumn{2}{|c|}{$\begin{array}{l}\text { A/R subjects } \\
\text { (sample, Wales } \\
\text { 1978) }\end{array}$} & \multirow{2}{*}{$\begin{array}{c}\begin{array}{c}\text { General population } \\
\text { England and } \\
\text { Wales (1981, } \\
\text { census) }\end{array} \\
\%\end{array}$} \\
\hline & No & $\%$ & No & $\%$ & \\
\hline $\begin{array}{l}\text { Class I } \\
\text { Class II } \\
\text { Class III } \\
\text { Class IV } \\
\text { Class V }\end{array}$ & $\begin{array}{r}6 \\
16 \\
9 \\
1 \\
5\end{array}$ & $\begin{array}{r}16 \\
43 \\
24 \\
3 \\
14\end{array}$ & $\begin{array}{l}1 \\
13 \\
42 \\
18 \\
17\end{array}$ & $\begin{array}{l}1 \\
14 \\
46 \\
20 \\
19\end{array}$ & $\begin{array}{r}6 \\
23 \\
49 \\
17 \\
5\end{array}$ \\
\hline Total & 37 & & 91 & & \\
\hline
\end{tabular}

small overdose, and none had required long term treatment. One at risk woman recalled having had psychiatric treatment as a child but could remember no details. Two spouses (wives) gave a history of psychiatric symptoms: mild postnatal depression and a phobic anxiety state. Only the latter had required psychiatric intervention. This subject represented the only psychiatric referral in the series, since it was thought that her condition might be caused or exacerbated by her conflict over having children.

Since entering the study a previously healthy at risk woman has developed a severe anxiety state, requiring psychiatric intervention, but has recovered two years later. At the time of referral three subjects at risk (two women, one man) were thought, by two experienced observers, to be showing subtle features which could indicate prodromal HD. Two other men have developed similar signs since being referred and one has had the diagnosis of HD confirmed. It is of interest that three of these patients had given a history of significant psychiatric disturbance. All five have continued to seek prenatal testing and two low risk children have been born to them.

\section{Exposure to $H D$}

All couples had known about their at risk status for from one to 10 years and all except two had had more than one source of information about HD. They had seen at least one affected person in the family and a very high proportion had seen at least one recent television programme on the disorder. Generally, they were well informed about the hereditary aspects.

\section{Attitudes towards presymptomatic testing}

Only $13(35 \%)$ of the subjects at risk said they would take a presymptomatic test (table 5) and six of their spouses disagreed; four spouses doubted if they could live with a positive result and two doubted if their partners could. Nearly half $(46 \%)$ were certain that they did not want prediction for themselves and none of the spouses disagreed. The proportion of men wanting presymptomatic testing was almost double the number of women; this may indicate a desire on

Table 5 Attitudes towards presymptomatic testing (study group only).

\begin{tabular}{lcccc}
\hline & In favour & $\begin{array}{l}\text { Not in } \\
\text { favour }\end{array}$ & Uncertain & Total \\
\hline $\begin{array}{l}\text { Females } \\
\begin{array}{l}\text { Males } \\
\text { All at }\end{array}\end{array}$ & 5 & 12 & 4 & 21 \\
$\begin{array}{l}\text { risk subjects } \\
\text { Partners } \\
\quad \text { (both sexes) }\end{array}$ & $73(35 \%)$ & $17(46 \%)$ & $7(19 \%)$ & 16 \\
Total & $20(27 \%)$ & $23(62 \%)$ & $7(19 \%)$ & 37 \\
\hline
\end{tabular}


the part of men in this selected group to try to spare their wives unnecessary intervention in pregnancy.

For seven subjects at risk, the major reason given for wanting prediction was to reduce uncertainty, and, for four subjects, to make decisions in relation to childbearing, that is, whether to have any children at all or further children, whether to undergo prenatal testing, or to decide on the timing of pregnancies. Three women remarked that if they knew they would be affected they would have their children as quickly as possible so that they could bring them up before onset of symptoms. The remaining two subjects wanted to know their status for the sake of children already born, but not necessarily immediately. One of these, a woman, has two children, only the second one of which has been tested prenatally and is at low risk. She says she intends to seek presymptomatic testing when her first born child, now an infant and currently at close to $25 \%$ risk, is in her late teens.

Seven at risk subjects wanted both tests but at different times and for different reasons. They wanted prenatal testing now and presymptomatic testing, to reduce uncertainty, some years hence, when they would be more able to tolerate an adverse result. It was pointed out to them that presymptomatic testing could show that a termination had been needless.

Nine couples had an uncertain or negative attitude towards both exclusion and presymptomatic testing. Five couples would have preferred presymptomatic testing to exclusion testing but three had a clearly inadequate family structure.

\section{Understanding of exclusion testing}

All couples received full counselling before blood samples were taken and typed. Nevertheless, on follow up, only four couples $(11 \%)$ had completely understood the implications of exclusion testing: nearly $90 \%$ were confused or had not grasped some details, for example, they knew they had been told that the at risk parent's risk did not change but could not explain why. Thus, some had begun to doubt what they had heard, particularly if they were also uncertain about the risk status of a fetus with an adverse result and believed that this meant it carried the gene which, in effect, would have diagnosed the parent. Others understood that the fetus' risk could be raised to that of the parent, but not the reason why termination of pregnancy was recommended in such an event. The implications of these findings are discussed later.

The information about chorion villus sampling and the residual risk to the fetus with a negative result was understood and retained by $30(81 \%)$ and $34(92 \%)$ of couples respectively.

Reasons for requesting exclusion testing

At the time of referral, all the couples counselled, except one, were motivated by one or both of the following reasons: (1) to seek information about the testing procedure, (2) to have a child of their own, predicted to be at low risk of carrying the HD gene. As discussed earlier, the only request which was refused was for the status of the child to be assessed.

This group were currently only interested in having children that were biologically their own. Some had already considered other options; five couples would have adopted had it been possible. None had wished to consider fostering. Four couples had seriously discussed AID but none had actually attended the relevant clinic and the wives were averse to the procedure. Two of these couples were prepared to look at AID again in the future if, in one case, further testing using different probes still proved uninformative, and, in the second, if predictive testing for the husband became possible and gave an adverse result.

A number had seriously considered having no children at all until they heard of the test, and most desired to limit their family size to one or two children at the most.

\section{Discussion}

Our initial reports ${ }^{10} 11$ suggested that exclusion testing in pregnancy, using linked DNA probes, was both feasible and acceptable ${ }^{14}$ and further analysis confirms this to be the case. However, it is impossible to estimate from this series what the future demando for it will be. Out of a total of 90 couples referred between April 1986 and April 1989, 61 have been tested for clinical purposes and found to be informative on pre-pregnancy testing. Thirty-five couples have withdrawn, 16 of these before testing was begun, seven when the results were not fully informative, and 12 after being given an informative result. Fifteen women have chosen prenatal testing in 24 pregnancies.

However, our figures cannot be taken as indicative of the probable future demand for exclusion testing. First, the study group is known to be a selected group, showing a bias in terms of social class and education, and it is likely that this is true of the series as a whole. It is reasonable to suppose that exclusion testing will be less favoured in an HD population at large.

Secondly, demand is likely to be influenced by the availability of presymptomatic testing. The attitudes expressed in this survey seem to indicate that some subjects will choose presymptomatic testing as a first option and only consider prenatal testing if their results show them to be at increased risk or their family structure is inadequate for prediction for themselves. Others will choose prenatal testing as a first option but will turn to presymptomatic testing if termination has been necessary, as one at risk man has already done in this series. Sequential use of the two approaches, with presymptomatic testing undertaken 
only where the exclusion test result gives a raised risk, is a further option where the family structure permits, as suggested recently by Fahy et al. ${ }^{15}$

One of us (AT) surveyed an unselected sample of 50 couples, where one partner was at $50 \%$ risk, living in South Wales. ${ }^{16}$ It was found that $20(40 \%)$ were prepared to consider prenatal testing though six of these had considerable doubts about whether their attitude would remain the same when they actually became pregnant. Thus, the future demand for prenatal testing is unknown, but is likely to be relatively small.

Our experience, though limited, suggests some of the conditions under which exclusion testing in pregnancy should take place. Referrals should be made preferably at least six months in advance of planning a pregnancy to permit the collection of blood samples and the typing of the DNA to be completed and for the necessary counselling to be undertaken. While most results can now be obtained in under six months some will take longer, for example, where extra blood samples are needed. For five women, four of whom were referred when already pregnant and one who conceived very shortly afterwards, fully informative results were obtained within one month for two of them, but not for the remaining three women.

A couple usually preferred to maintain a detached attitude towards the pregnancy and not to inform friends and relatives until the result of the chorion biopsy was known, and to continue the secrecy if a termination was necessary. In this circumstance, obviously, confidentiality needs to be scrupulously maintained, which can need considerable vigilance if genetic staff are already known to and are in contact with the extended family. Arrangements for clinic appointments, sending letters, and making and receiving telephone calls may need to be carefully scrutinised beforehand to avoid arousing suspicion.

If unexpected delays in giving a result occurred, either in the pre-pregnancy stage or (in two cases) after chorion villus biopsy had been performed, most consultands needed to be reassured that the delay was not because of "something wrong with their blood" but technical problems in the laboratory beyond their control. Reassurance was also often needed when a fetus was given a raised risk, as some subjects felt that their own risk had also been raised.

In the event of an adverse prenatal test, termination needs to be offered with the minimum of delay and at the same time as the result is given. On two occasions it proved necessary to review our procedure with our Welsh patients when the results were 'guessed' beforehand: once when a home visit was made as the quickest method of communicating the result, and on a second occasion when the clinic appointment was made not in the Genetic Centre but in the antenatal clinic.
The ethical issues surrounding prenatal exclusion testing have received scant attention to date. ${ }^{10} 1617$ Arguably the most important concerns termination of pregnancy when the fetus shares the same risk as the parent.

Although a child who shares his parent's risk has an equal chance of being unaffected, should the parent develop signs of HD the child is known immediately to be at very high risk of also being a gene carrier. This risk alteration is not under the child's control and effectively removes from him freedom of choice regarding knowledge of his own-status, which many centres believe belongs to him. ${ }^{17} 18$ International guidelines, which state that a presymptomatic test should only be offered to freely consenting adults, support this view. ${ }^{19}$

Counselling is therefore obviously extremely important in ensuring that couples understand the issues involved and specifically that termination of a possibly unaffected fetus may occur. A striking finding of this study was the great difficulty experienced, even by well educated couples, in completely understanding the information given, as $89 \%$ needed repeated explanations. Written material was helpful but no substitute for discussion.

Other aspects of counselling included the possible psychological consequences for the parents and child if the status of the two was linked. Couples were invited to consider how they might feel if the parent at risk and his offspring were, in effect, 'diagnosed' simultaneously. There is also the question of the anxiety which they could feel even if the parent never developed any signs of HD. Many at risk persons 'symptom search'20; in the authors' experience those who do not feel any anxiety about their at risk status are not likely to be motivated to seek testing. It can be assumed, therefore, that their anxiety about themselves would be heightened if it was thought that their child could also be implicated. The psychological effects of this anxiety both on the parent and the child are unknown. There is also the question that a child known to be at very high risk of carrying the gene (if his parent became affected) could be at risk of being discriminated against with regard to educational and employment opportunities. ${ }^{21-23}$

These aspects will assume even greater importance when subjects with an adverse result on presymptomatic testing seek prenatal testing. Four recent American studies, ${ }^{17} 182425$ which surveyed attitudes towards prenatal testing found that $32 \%$ to $65 \%$ said they would use it. A worrying finding in three of these studies was the number of at risk subjects in this group (63\% to $71 \%$ ) who said they would continue with a pregnancy even if they themselves had been given a positive result on presymptomatic testing and the fetus had been found to share the same risk.

All four surveys attempted to estimate the level of knowledge possessed by their participants. The 
number in favour of continuing with a pregnancy in such circumstances appeared to be in inverse relationship to their level of understanding. Kessler $e t a l^{24}$ remarked that $79 \%$ had not received genetic counselling, and that "the level of information was surprisingly low"; $71 \%$ of this group was uncommitted to termination of pregnancy. Meissen and Berchek ${ }^{25}$ also commented on the low knowledge of predictive testing and that nearly half of those who could not answer any knowledge questions correctly intended to use the prenatal test; $66 \%$ might not abort whatever the result. Markel et $a l^{17}$ found the level of knowledge high (but did not ask questions specific to prenatal test understanding); $63 \%$ were unhappy about termination. Mastromauro et al ${ }^{18}$ did not ask specifically about respondent's attitudes to termination of pregnancy but commented that the level of knowledge about testing was good; it is noteworthy that their survey contained the lowest percentage number $(32 \%)$ who said they would use prenatal testing.

We wonder whether the surprising finding that so many in the American studies say they would continue with a very high risk pregnancy is related to the amount and type of counselling received. The problem did not arise in the present series since all 10 high risk pregnancies were terminated, but one high risk pregnancy which was not terminated has been reported elsewhere. ${ }^{26}$ Continuing studies are needed to discover what percentage of pregnancies, with adverse results, come to term and what will be the effects on the parents and children.

Some evidence is available that women seeking termination for genetic reasons can suffer intense and prolonged grief which, if unresolved, can affect their health and attitudes towards future children. ${ }^{27}{ }^{28}$ All the Welsh patients were followed up after termination and offered bereavement counselling, but none accepted, although some couples commented that it had been very helpful to know that two of the authors (AT and OQ) were available to give support. None seemed to suffer more than transient feelings of loss. This may be partly because, in all cases except one, termination was carried out in the first trimester, in contrast to the earlier studies when fetal testing was by amniocentesis and termination was performed at a later stage. Also all these women were motivated to try again and all have achieved low risk pregnancies, except two; one of these women has been waiting for the result of presymptomatic testing on her at risk husband before embarking on a second pregnancy.

Women who received a low risk result and whose pregnancies came safely to term universally experienced gladness and delight. If they had undergone previous terminations they felt that their previous 'sacrifices' had been worthwhile, and several couples commented that they had been brought closer together by the experience.

The position of children in the same family, who have differing risks owing to prenatal testing having been undertaken for one but not the other(s), has implications for counselling. This has happened once in this series and will undoubtedly happen again. Follow up studies are needed since it is conceivable that family attitudes towards them would differ, with adverse implications for the untested child, particularly if it became known that the at risk parent was a gene carrier and the child's risk, therefore, was further raised.

Some of the findings of this survey have implications for presymptomatic pre-test counselling and testing. Subjects requesting presymptomatic testing, after having used prenatal testing, could discover that a termination had been unnecessary. This situation could have occurred in this study if the at risk person had not been given an increased risk.

It was also helpful to discover that almost half of the spouses of persons at risk who were in favour of presymptomatic testing held a different viewpoint and did not want their partners to be tested. A similar lack of concordance was found in a smaller study in Belgium $^{29}$ where only seven out of 18 couples were in complete agreement. Considering the implications of a positive result, it might be considered hazardous to the marital relationship to proceed with testing while disagreement exists.

Problems relating to premature knowledge of a test result can arise if a person at risk, whose DNA has already been typed, later requests presymptomatic testing. In the case already described, a careful procedure was worked out, which involved not typing an affected member until a late stage, in order to avoid knowing the applicant's status before pre-test counselling had been completed.

Another problematical situation relates to sibs, two pairs of which presented in this series, both of whom were informative for prenatal testing. Each sib held opposing views on the question of presymptomatic testing for themselves. Altering the risk for one could lead to an automatic risk alteration for the other, who had not requested it, because DNA typing results for both would be available. It is also conceivable that it would be possible to discover whether further prenatal testing is necessary. Inadvertent risk alteration can also occur if too much information is gathered in the course of pregnancy exclusion testing. ${ }^{30}$ These problems raise issues of confidentiality and the testing centre's contract with consultands, to name but two. It is suggested that protocols to meet these situations be incorporated into testing programmes.

Prenatal testing can confer benefits upon couples who, otherwise, might have been deterred from childbearing because of worries over their risk status. It can also carry with it certain hazards and raise ethical problems, some of which may become pressing as presymptomatic testing becomes more widely used. Follow up studies are needed, together with contin- 
uous evaluation of protocols and guidelines, to meet these challenges.

We thank our many colleagues in clinical genetics throughout Britain who referred their patients and also our colleagues in the Obstetric Department for help in undertaking the chorion biopsies. This work was supported by grants from the Medical Research Council and from the Mental Health Foundation.

1 Gusella JF, Wexler NS, Conneally PM, et al. A polymorphic DNA marker genetically linked to Huntington's disease. Nature 1983;306:234-8.

2 Harper PS, Quarrell OWJ, Youngman S. Huntington's disease: prediction and prevention. Philos Trans $R$ Soc Lond 1988;13319: 285-98.

3 Harper PS, Sarfarazi M. Genetic prediction and family structure in Huntington's chorea. $\mathrm{Br} \mathrm{Med}$ f 1985;290:1929-31.

4 Craufurd DIO, Harris R. Ethics of predictive testing for Huntington's chorea: the need for more information. $\mathrm{Br} \mathrm{Med} \mathcal{J}$ 1986;293:249-51.

5 Farrer AL. Suicide and attempted suicide in Huntington's disease: implications for preclinical testing of persons at risk. Am f Med Genet 1986;24:305-11.

6 Lamport AT. Presymptomatic testing for Huntington's chorea: ethical and legal issues. Am F Med Genet 1987;26:307-14.

7 Farrer LA, Myers R, Cupples LA, Conneally PM. Considerations in using linkage analysis as a presymptomatic test for Huntington's disease. 7 Med Genet 1988;25:577-88.

8 Meissen GJ, Myers RH, Mastromauro CA, et al. Predictive testing for Huntington's disease with use of a linked DNA marker. $N$ Engl f Med 1988;318:535-42.

9 Hayden MR, Robbins C, Allard D, et al. Improved predictive testing for Huntington's disease by using three linked DNA markers. Am 7 Hum Genet 1988;43:689-94.

10 Quarrell OWJ, Meredith AL, Tyler A, et al. Exclusion testing for Huntington's disease in pregnancy with a closely linked DNA marker. Lancet 1987; i:1281-3.

11 Meredith AL, Upadhyaya M, Lazarou LP, et al. Molecular genetics in clinical practice-the evolution of a DNA diagnostic service. Br Med J 1988;297:843-6.

12 Tyler A, Harper PS. Attitudes of subjects at risk and their relatives towards genetic counselling in Huntington's chorea. f Med Genet 1983;20:179-88.

13 National Report. Great Britain, Part 2. 1981. Census, London: HMSO Office of Population Censuses and Surveys, 1981
14 Hayden MR, Hewitt J, Kastelein JJP, et al. First trimester prenatal diagnosis for Huntington's disease with DNA probes. Lancet 1987;ii:1284-5.

15 Fahy M, Robbins C, Bloch M, et al. Different options for prenatal testing for Huntington's disease using DNA probes. I Med Genet 1989;26:353-7.

16 Tyler A. Genetic counselling in Huntington's chorea. In: EversKiebooms G, et al, eds. Genetic risk, risk perception and decision making. New York: Alan R Liss, 1987:85-95.

17 Markel DS, Young AB, Penney JB. At-risk persons' attitudes toward presymptomatic and prenatal testing of Huntington's disease in Michigan. Am f Med Genet 1987;26:295-305.

18 Mastromauro C, Myers RH, Berkman B. Attitudes toward presymptomatic testing in Huntington's disease. Am $\mathcal{F} \mathrm{Med}$ Genet 1987;26:271-82.

19 Ethical issues policy statement on Huntington's disease molecular genetics predictive test. Report of an ad hoc committee. $\mathcal{F} \mathrm{Med}$ Genet 1990;27:34-8.

20 Wexler NS. Genetic "Russian Roulette": the experience of being "at risk" for Huntington's disease. In: Kessler S, ed. Genetic counseling: psychological dimensions. New York: Raven Press, 1979:199-220.

21 Berg K, Fletcher J. Ethical and legal aspects of predictive testing. Lancet 1986;i:1043.

22 Morris M, Tyler A, Harper PS. Adoption and genetic prediction for Huntington's disease. Lancet 1988;ii:1069.

23 Tyler A. Adoption policy in relation to presymptomatic testing for Huntington's disease. Adoption and Fostering 1988;12: $52,57$.

24 Kessler S, Field T, Worth L, Mosbarger H. Attitudes of persons at risk for Huntington's disease toward predictive testing. $A m \mathcal{F}$ Med Genet 1987;26:259-70.

25 Meissen GJ, Berchek RL. Intended use of predictive testing by those at risk for Huntington's disease. Am $\mathcal{f}$ Med Genet 1987;26:283-93.

26 Brock DJH, Mennie M, Curtis A, et al. Predictive testing for Huntington's disease with linked DNA markers. Lancet 1989;ii: 463-6.

27 Donnai D, Charles N, Harris R. Attitudes of patients after 'genetic' termination of pregnancy. Br Med f 1981;282:621-2.

28 Morgan C. Bereavement counselling for genetic terminations of pregnancy. Unpublished paper presented to a meeting of the Genetic Nurses and Social Workers Association, Institute of Medical Genetics, Cardiff, 1986.

29 Evers-Kiebooms G, Cassiman JJ, Van den Berghe H. Attitudes towards predictive testing in Huntington's disease: a recent survey in Belgium. F Med Genet 1987;24:275-9.

30 Millan FA, Curtis A, Mennie M, et al. Prenatal exclusion testing for Huntington's disease: a problem of too much information. $\mathcal{J}$ Med Genet 1989;26:83-5. 